lucid and concise. Evidence for the genetic factor in schizophrenia, affective disorders, psychopathy and neurosis, is clearly set out in the summary, and the reader can examine it and draw his own conclusions.

In their final paragraph the authors say 'A study of the personalities of the twins in all clinical groups shows that the basic make-up of the personality is largely determined by heredity.' This generalization may be true, but it is not warranted by the clinical material here presented. Proof of this proposition would require an examination of the life-patterns of twins with the same genetic make-up reared in contrasting environments from birth. In the series studied in this book only three pairs of twins were separated from each other in early life. .These three were binovular or non-identical twins. All that can be said, therefore, is that twins reared in the same family may show similarities, how much of this similarity is due to heredity and how much to environment is now, and I expect will remain, an open question.

$$
\text { D.O'N. }
$$

\section{AN APPROACH TO GENERAL PRACTICE}

By R. J. F. H. Pinsent, M.A., M.D. Pp. viii + 166. Edinburgh. E. \& S. Livingstone Ltd. 1953. I2s.

As the author points out, few students enter medicine with the avowed intention of becoming general practitioners. Most would prefer to spend their lifetime in the hospital atmosphere which has already become familiar to them, because they have had little opportunity of seeing the other side of the medal. This Dr. Pinsent succeeds in showing, with a comprehensive picture of general practice as it is today.

The early chapters contain many useful hints for the novice, ranging from medical ethics to equipping the G.P.'s bag and consulting room. Although a full chapter is given to a description of the formidable number of forms in current use in the N.H.S., the human side of medicine is not forgotten, and the recently qualified doctor who is contemplating entry into general practice will not only be encouraged but will find a wealth of valuable information in this book.

P.M.B.

\section{A DICTIONARY OF MIDWIFERY AND PUBLIC HEALTH}

By G. B. Carter, B.Sc.; S.R.N., S.C.M., M.T.D., and G. H. DoDDs, M.D., F.R.C.S., F.R.C.O.G. Pp. 686, illustrated. London: Faber \& Faber Ltd. 1953. 25s.

The authors must be congratulated on producing this book which is full of useful, concise facts and sound, up-to-date practical advice. This is much more than a dictionary, the section of breast feeding, for example, being over seven pages long with four illustrations. The vast majority of these discussions are first class, the ones on uterine inertia, anuria and pre-eclampsia being especially commendable.
About roo pages are devoted to public health and administration, and the field covered ranges; from ' UNESCO' ' at one extreme to 'iscabies' at the other.

Only very occasionally does the book lapse into its most likely pitfall, that of long hypothetical lists - thus eighteen causes of abortion are enumerated, of which six are dubious in the extreme.

However, this is a book which not only might well be in every labour ward sister's office, but could also be studied to advantage by the medical practitioner.

\section{D.W.S.G.}

\section{APPLIED CYTOLOGY}

By G. R. Osborn, M.B., B.S. Pp. xi +168 , with 131 illustrations. London: Butterworth and Co., Ltd. I953. 35s.

This books gives an account of the technique and criteria adopted for the cytological diagnosis of cancer of the uterus, bronchus, breast and bladder. The main part of the work is devoted to the first of these, in which the author appears to have considerable experience. Much valuable information is given including the shortcomings of the methods.

The chief criticism of the work is that a much more detailed correlation between cytological diagnosis, histology of the biopsy and examination of the gross specimen when available could have been made. Such correlation is essential in assessing the accuracy of purely cytological'methods of diagnosis.

The book is profusely illustrated with excellent photographs.

R.H.H.

\section{THERAPEUTICS IN INTERNAL MEDICINE}

Edited by F. A. KYSER, M.D., F.A.C.P. 2nd

Edition. Pp. xxi +830 . London: Cassell \&

Co., Ltd. I953. I Ios.

This book is a reliable guide to therapeutics and can be recommended. It consists of a series of articles on the treatment of practically every known disease. These have been written by some 84 American physicians. The only real criticism that can be levelled at the book is one that can be levelled against any textbook of therapeutics, namely that treatment cannot be discussed without extensive reference to the nature of the condition being treated. Any textbook of therapeutics must therefore, of necessity, also be a textbook of medicine. The authors of this book have clearly realized this and they have frequently included brief sketches of the diseases the treatment of which they describe, but the result can never be as satisfactory as a textbook dealing in detail with both medicine and therapeutics. However, for those who prefer a single volume of therapeutics this is more successful than most. The standard of the individual articles is uniformly high. Two perhaps call for special mention: a delightful article on the treatment of psychosomatic problems by Dr. Walter Alvarez, 
and a section on the difficult subject of electrolyte disturbances and their treatment by Dr. Irwin Winter. This subject is usually badly dealt with and the inclusion of this article will be of considerable help to anyone, called upon to administer parenteral fluid therapy.

\section{RRITISH MEDICAL SCIENCE AND PRACTICE-AN ANTHOLOGY}

Arranged and edited by G. F. Petrie, M.D. Pp. $\mathbf{x v i}+172$, illustrated. London: Longmans, Green \& Co., Ltd. I953. I 5 s.

This anthology is a pleasant compilation of the writings of British medical men and British scientists who have worked on medical subjects. The book was conceived by the British Council towards the and of the recent war ' with the object of helping doctors and students abroad to follow modern trends in medicine as it is practised in England.'

The book falls into three parts. The first consists of biographical notes on famous figures in the history of British medicine: William Harvey, John Hunter, Edward Jenner, Sir Charles Bell, Richard Bright, Thomas Addison, Sir James Young Simpson, Florence Nightingale, Lord Lister and Sir Patrick Manson. This is followed by a collection of aphorisms culled from hte writings of famous British medical men. The third, and much the largest part of the book, consists of extracts from the writings of contemporary British medical men and scientists, chosen by the authors themselves.

This anthology constitutes an excellent bedside book and may for many of us supply the answer to the knotty problem 'What shall we give him for Christmas?'

ENZYMATIC CONCEPT OF ANAPHYLAXIS AND ALEERGY

By Z. Z. Godlowski, M.D., Ph.D., M.R.C.P. Pp. viii +120 , with 17 illustrations, many in colour. Edinburgh: E. \& S. Livingstone Ltd. 195.3. $15 s$.

This short monograph summarizes the author's unorthodox views on anaphylaxis and allergy. As Professor Murray Drennan states in his preface, - It may perhaps be objected that there is more theorizing than the facts merit.' But although, for this reason, it is definitely not a book to be. read by students, yet the views expressed will certainly be found stimulating to research workers in this difficult field. The author's views on eosinophilia are illustrated b.y a series of beautiful colour photomicrographs. The book is well produced and affords yet a further example of the high standards we have grown to expect from the firm of $E$. \& $S$. Livingstone.

In our December issue we reviewed 'Elementary Pathological Histology' by Professor Barnard. If this review we noted that some pages were omitted and others duplicated. We understand from the 0 publishers, H. K. Lewis \& Co. Ltd., that this was a binder's error peculiar to the copy sent to us.

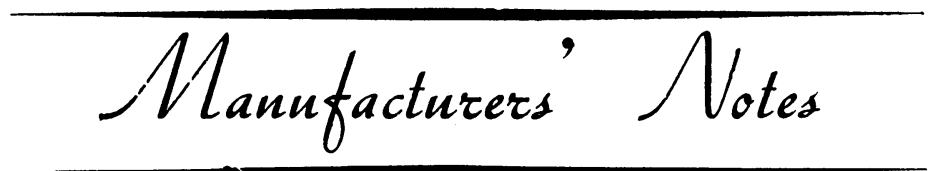

\section{'PAREDRINEX'}

Menley \& James, Limited, Coldharbour Lane, London, S.E.5, announce the introduction of "Paredrinex" Plain. This vasoconstrictor for intranasal use has: not hitherto been available on its own, although it is a major component of 'Sulfex' and 'Pendex,' in which it is combined with sulphathiazole and penicillin respectively. "Paredrinex" is for promoting ventilation and drainage when there is nasal congestion. As it does not impair ciliary movement it is particularly effective in restoring normal activity to the nasal passages. The central nervous side-effects associated with ephedrine-like compounds do not appear, and it shows great superiority in rapidity and duration of action.

Menley \& James, Limited, Coldharbour Lane, London, S.E.5, announce that 'Iodex ' (Plain) and 'Hodex' (Green Label) cum methyl salicylate are now available in $\mathrm{I}-\mathrm{Oz}$. collapsible tubes instead of $1-0 z$. jars. The 4-oz. pack in jars remains unchanged.
Burroughs Wellcome \& Co. announce the introduction of 'Wellcome' brand DiphtheriaTetanus-Pertussis Prophylactic (D.T.P.P.). Like the recently introduced 'Wellcoma' DiphtheriaPertussis Prophylactic, this preparation contains no alum or other mineral carrier. Both preparations are identical in price. Hence children can be actively immunized against tetanus in addition to diphtheria and whooping cough at no extra cost or inconvenience. It is issued in sets of three $I$ cc. ampoules or rubber-capped bottles of $10 \mathrm{cc}$.

Burroughs Wellcome \& Co. announce that the new 'Wellcome' brand Insulin Zinc Suspension N -Lente, 40 and 80 units per c.c.; 'Wellcome ' $O$ brand Insulin Zinc Suspension (amorphous)Semilente, 40 units per c.c.; and 'Wellcome ' brand Insulin. Zinc Suspension (crystalline)Ultralente, 40 units per c.c.; will be available as 0 from Monday, November 16: Each will be issued in vials of 10 c.c. 